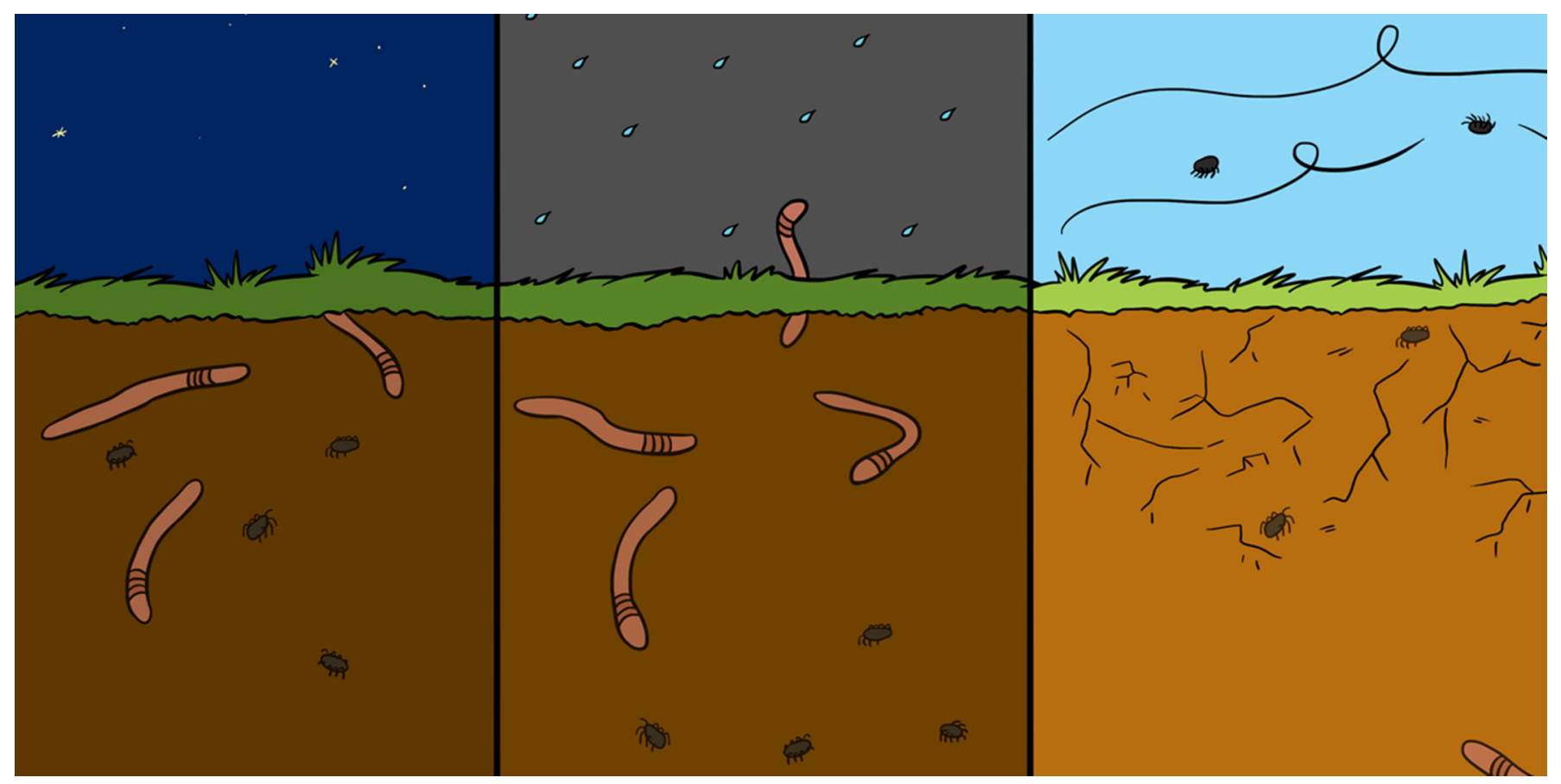

\title{
SOIL ECOSYSTEMS CHANGE WITH TIME
}

\section{Enrique Doblas-Miranda *}

CREAF, Bellaterra (Cerdanyola del Vallès), Barcelona, Spain

YOUNG REVIEWERS:

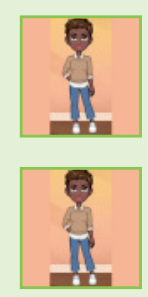

RUTENDO

AGE: 14

NOKUTENDA

AGE: 14
All the animals living below our feet are not still. They can move (to a lot of places because the soil is a 3D space) and to change (for example, from a cocoon to an active state). Therefore, the same soil below a given piece of field may not contain the same living communities in winter as in summer, or even during a sunny day compared to a cold night. For example, research on soil beetle larvae showed seasonal vertical movements, as the larvae searched for better living conditions. Moreover, the soil varies a lot during its formation, and consequently its inhabitants also change. In the case of oribatids, a minuscule but diverse group of soil mites, scientists observed changes in the community over dozen to hundreds of years! Many studies showed a basic but powerful principle: ecosystems are not still photographs, but instead are constantly changing environments.

\section{ECOSYSTEMS ARE NOT STATIC PHOTOGRAPHS}

When we imagine ecosystem diversity, we often picture ecosystems as mostly stable and unchanging, like photographs in a book, with all the 


\section{SOIL BIODIVERSITY}

The total variety of living creatures inhabiting soils.

\section{INVERTEBRATES}

Animals with no bones In the soil, that means mainly worms and arthropods (centipedes, woodlices,

insects, spiders...).

\section{SOIL PORES}

Extremely small $(<0.075 \mathrm{~mm})$ spaces in the solid structure of the soil, filled mainly with air and water [1].

\section{VERTICAL}

\section{MIGRATION}

Vertical migration is typical of soil and aquatic environments, where mobile organisms are not limited to move over a (horizontal) surface. Like any other migration, it is normally guided to find resources or better environmental conditions.

\section{SOIL MESOFAUNA}

Soil inhabitants, smaller than $2 \mathrm{~mm}$, such as springtails, mites, and tiny worms [2].

\section{PASSIVE DISPERSAL}

Mobile organism can move actively (using their legs or appendices to go through the territory) or let themselves "go with the flow" (of water, wind or even other animals), which is call passive movement or dispersal. plants and animals existing in a frozen state of balance. In our heads (and in many book pictures), plants are readily available for herbivores to eat, and herbivores are waiting to be eaten by carnivores, all under wonderful daylight. But reality is not like that! Most of the animals in an ecosystem move during the day and some of them only appear at night. Plants produce different edible parts depending on the season. The entire ecosystem can even change due to catastrophes like forest fires. Not to mention, we rarely even imagine the diversity that happens in the soil under our feet.

\section{HOW CHANGE WORKS UNDER OUR FEET}

Of course, soil biodiversity also changes with time, although not necessarily the same way changes happen aboveground. First, movement is certainly more difficult in the soil. Earthworms, insect larvae, mole crickets (also moles, but we are going to focus on small invertebrates), and many other tiny creatures must dig with their mouths, claws, or legs. Smaller creatures move throughout the soil mainly using tiny air-filled spaces called soil pores.

Soil inhabitants are not limited to the typical horizontal movements of surface animals. Soil invertebrates can also move up and down beneath the same surface area, which is called vertical migration. Vertical migrations can occur during a single day, or across seasons. Enchytraeids, very tiny worms, are one of the few types of soil-dwelling animals that have been observed to migrate during the day. Enchytraeids move deeper into the soil to escape from dry surface conditions at midday and return from the deep in the evening, when their favorite moist conditions are reestablished. This migration is the basis of one of the most-used methods to study soil mesofauna. This method consists of drying a soil sample in a funnel with a light bulb at the top, so the creatures "escape" by falling to a collection container in the bottom (Figure 1).

Many soil invertebrates can exist in resistant forms that allow them to survive harsh conditions for a long time. Ground pearls, small, rounded, and very interesting insects, are a perfect example. They can secrete a pearly covering around themselves, forming a spherical cyst or "resting" stage, in which they can remain for decades! But when delicious roots are available, the cysts develop and become voracious adults. If conditions are really good, many ground pearl species can clone themselves to profit as much as possible from favorable conditions. An unlucky vineyard farmer may not see the tiny ground pearls 1 year, but find his crops infested with adults the next.

At the soil surface, many small animals can be carried by the wind, water, and even by other animals. Some surface-dwelling creatures travel this way as well, but the so-called passive dispersal of soil 


\section{Figure 1}

Isolating soil

invertebrates for study.

A typical Tullgren or

Berlese funnel trap,

named after its

inventors. The soil is

placed in the top of a

funnel, held up by a

layer of mesh. A light

bulb heats and dries the

soil, forcing the soil

organisms to go down.

When they drop from

the sample, they fall

into a collection

container, usually filled

with a substance that

keeps them alive. The

organisms can then be

studied.

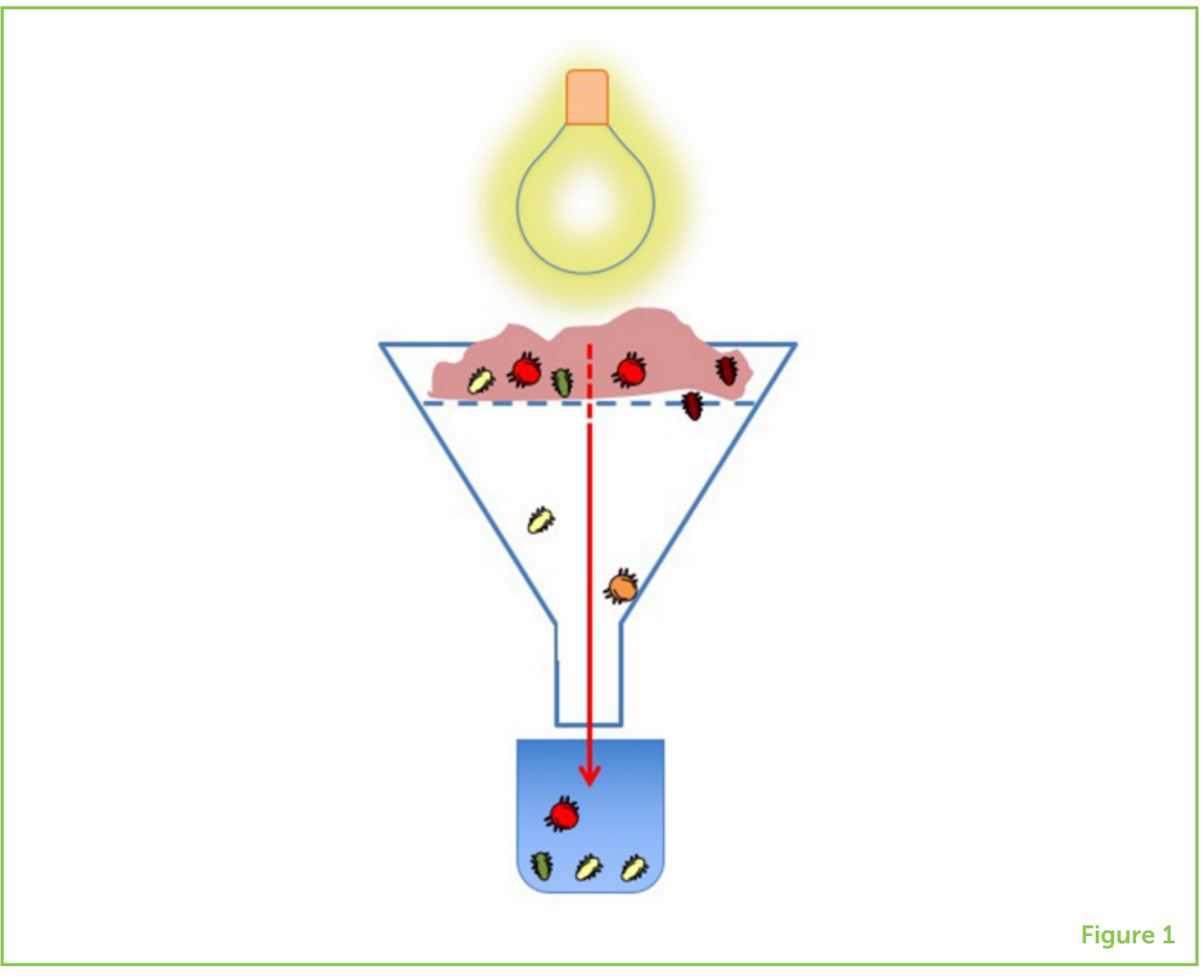

fauna has gained a lot of research attention lately, as it may explain movements of soil organisms across large distances.

\section{SEASONAL CHANGES}

During my early years as a researcher, movements of soil organisms were not as understood as they are today and every discovery was very exciting, including the discovery that some soil-living insect larvae perform seasonal vertical migrations [3]!

Soil was sampled in multiple locations every month for 2 years, in a desert-type shrubland in Southern Spain. Soil samples were collected at different depths, from the surface litter down to $50 \mathrm{~cm}$ deep. For each sample, all the macroinvertebrates were counted and identified. After analyzing all the samples, from every season and soil depth, scientists found that the larvae of one abundant beetle family called Tenebrionidae, which eat organic debris, made the same movement each year. They were more abundant at the soil surface in winter than they were in summer (Figure 2).

In the studied area, summers are very hot and dry. However, Tenebrionidae's favorite dish, litter debris, is found in exposed soil-surface "restaurants," like shrubs and ant mounds. Therefore, these beetle larvae prefer to devour surface litter debris during the winter's gentle weather, but enjoy other, deeper "restaurants," such 
Figure 2

Vertical migration of beetle larvae, depending on soil depth and season. In summer, the larvae are equally abundant at the surface and in the deeper levels of the soil, but in the winter they are much more abundant at the surface, where they can feed on leaf litter and not be damaged by the hot, dry conditions present in summer.

\section{ECOSYSTEM}

SUCCESSION

The process by which ecosystems are "born" and "grow" after the creation of new surfaces, like a new coral island or the soil revealed after glaciers melt, or how ecosystems "regrow" after disturbances like forest fires.

\section{CHRONOSEQUENCE}

A group of ecosystems studied at the same time, which are similar in origin, plant species, and geographical area, but have different ages. Studying ecosystems in chronosequence is necessary because we cannot wait decades to sample one ecosystem over the course of its development.

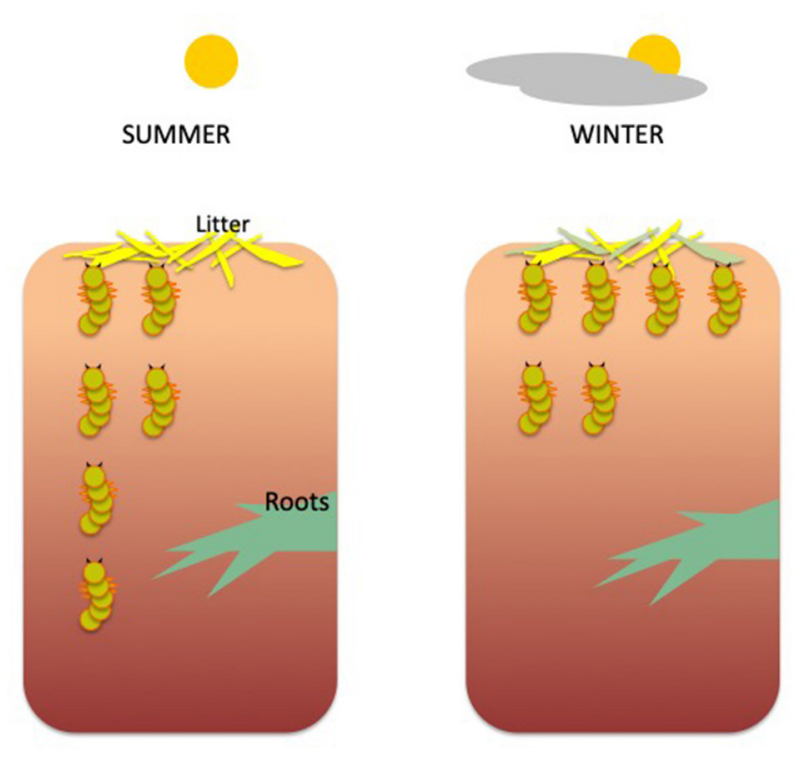

Figure 2

as decaying roots, in summer. When the larvae perform this vertical migration, they are also doing a great service for the entire ecosystem. Like earthworms in more humid ecosystems, these tough larvae move the soil in arid environments, so air, water, and organic materials are mixed in the soil, which is highly beneficial for soil health.

\section{ECOSYSTEMS CAN GROW... AND EVEN AGE!}

Changes in weather conditions and food availability are not the only changing features of ecosystems. In fact, an entire ecosystem can change during a process called ecosystem succession. Scientists have studied how the diversity of soil animals changes during ecosystem succession, focusing on a group of soil mites called oribatids. Oribatids are tiny, abundant, and diverse, which means that you can find an entire community of them in a small sample of soil. There are also many resources available to help identify various oribatid species, so they are a perfect organism to observe to study changes in soil ecosystem diversity. Also, the mobility of oribatids is relatively limited, since they exist in the deep soil are restricted to moving through soil pores and can occasionally move by passive dispersal. Therefore, oribatid communities mainly develop through the process of ecosystem succession.

In a recent study, scientists carried out in a chronosequence of forests that are re-growing after cropland abandonment. They wanted to know if similar forests of different ages have the same soil communities. Scientists hypothesized that croplands probably had only a few oribatid species in low abundances, but that complex communities with high diversity would develop in older forests. Comparing current aerial photographs with others from the 1950s, 
Figure 3

Ecosystems change and grow over time. In the 1950s (top), there were more abundant and rich communities of oribatids in the forest than in croplands. After crop abandonment (middle), individuals of some species from the forest arrived in the connected croplands mainly by passive dispersal (arrows).

Finally, the

disappearance (dashed arrow) of a few species, which probably needed a more developed soil, created the current differences among the three kinds of forests (bottom).

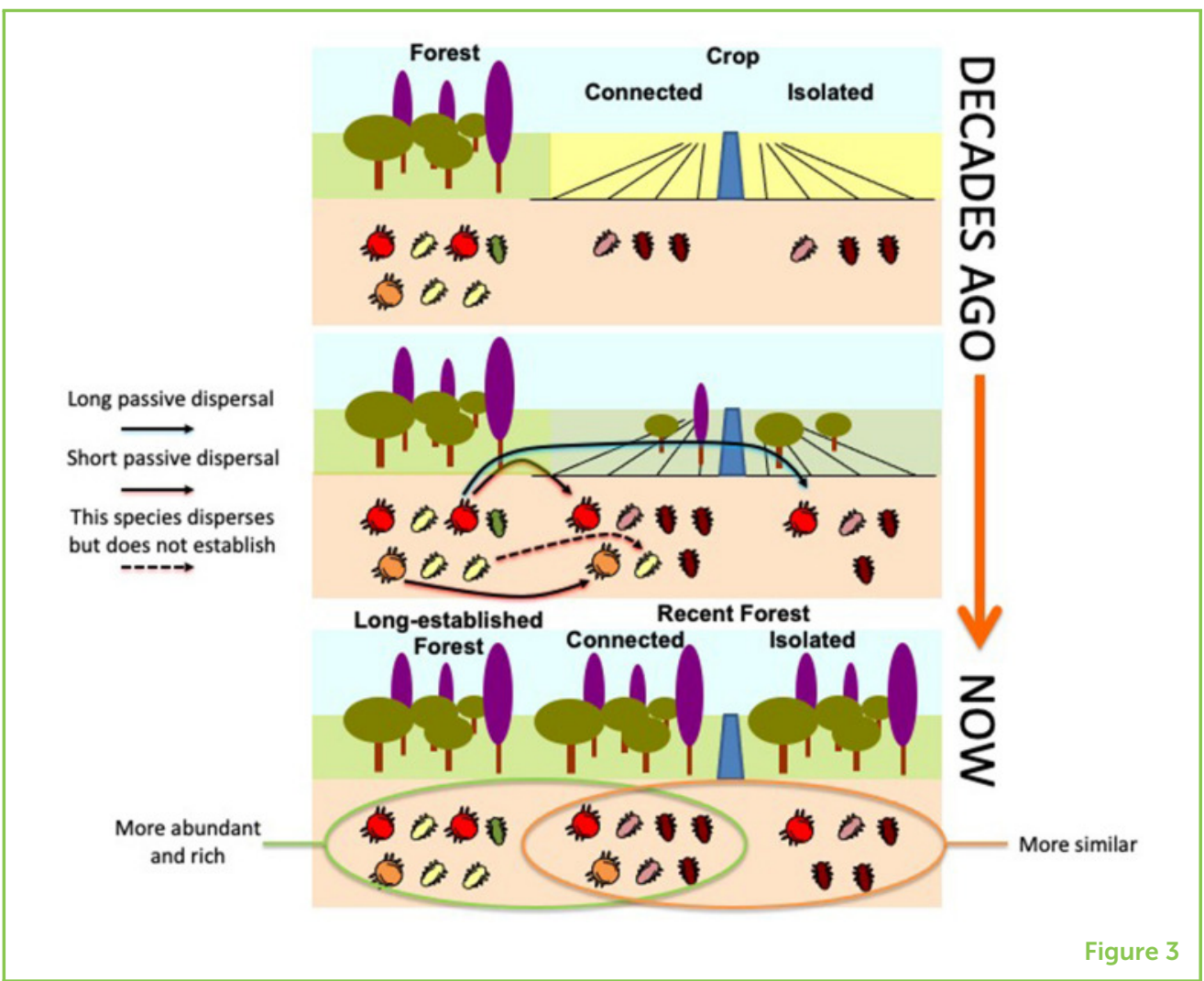

scientists determined which areas had been forests in the 1950s (long-established forests), and which had been croplands (recent forests). Among the recent forests, we also distinguished between isolated forests (surrounded mainly by croplands and most likely showing oribatid communities similar to those found in croplands) and those connected to other forests (probably with oribatid communities similar to those found in old forests).

Scientists observed two important results. First, long-established and recent but connected forests showed similar numbers of oribatids and similar numbers of species, which were higher than what was seen in the isolated forests. Second, oribatid communities in isolated and connected recent forests shared more species than they did with long-established forests (Figure 3, bottom). Likely, oribatids arrive mainly by passive dispersal early in ecosystem development. That is probably why recent forests connected to long-established forests quickly establish oribatid communities similar to those in the long-established forests. But as the recent forest ecosystem continues to develop, lack of refuge availability and access to food may prevent some oribatid species from permanently settling there. This could explain why oribatid communities in recent and connected forests are more like those of isolated forests and thus to those of croplands (Figure 3). 
Ecosystems not only "grow," but can also "age" if no major disturbance occur, such as fires. Scientists studied ecosystem aging in Canadian boreal forests [4]. They sampled oribatids in a chronosequence based on the time since the last forest fire, which was estimated from 100-year-old maps, tree rings from trees up to 200 years old, and chemical dating of deep soil, which was up to 700 years old! Although oribatid abundance was drastically reduced during the first 200 years of forest development after the last fire, the number of different species was not really affected until the later stages of forest aging. This means that the progressive diminution of nutrients as phosphor and nitrogen could not maintain abundant populations, and later on, not even entire populations of some species. Scientists also studied soil samples beneath tree logs and exposed soil and found that oribatids beneath logs were less abundant than those living in exposed soil, although maintained their populations stable. This led lead scientists to conclude that oribatids living on exposed soil were more affected by aging, probably because of a reduction in the availability of leaf litter as the forest aged.

\section{ECOSYSTEMS ARE LIKE PRECIOUS MOVIES}

I hope that now, when you imagine ecosystem diversity in a forest, you have more than just a still picture in your head, since all these living creatures change and move, appear and vanish...and I hope that you also imagine the creatures inhabiting the soil beneath our feet! Ecosystems, as living scenarios, are not static but are highly dynamic over time. The tiny, diverse creatures living in the soil change with the ecosystems, using many different and amazing strategies. Soil-living creatures are especially important for the ecosystem, as they maintain soil health and are a critical part of the recycling of dead leaves and roots, a process that actually helps to reduce global warming and contributes to the health of our entire planet.

\section{REFERENCES}

1. Nielsen, U. (Ed.). 2019. "Soil and its fauna," in Soil Fauna Assemblages: Global to Local Scales (Cambridge: Cambridge University Press). p. 1-41. doi: 10.1017/ 9781108123518.002

2. Orgiazzi, A., Bardgett, R. D., Barrios, E., Behan-Pelletier, V., Briones, M. J. I., Chotte, J. L. et al. (Eds.). 2016. Global Soil Biodiversity Atlas. Luxembourg: Publications Office of the European Union.

3. Doblas-Miranda, E., Sánchez-Piñero, F., and González-Megías, A. 2009. Vertical distribution of soil macrofauna in an arid ecosystem: are litter and belowground compartmentalized habitats? Pedobiologia 52:361-73. doi: 10.1016/j.pedobi. 2008.11.006

4. Doblas-Miranda, E., and Work, T. T. 2015. Localized effects of coarse woody material on soil oribatid communities diminish over 700 years of stand development in black-spruce-feathermoss forests. Forests 6:914-28. doi: 10.3390/f6040914 
SUBMITTED: 17 March 2020; ACCEPTED: 12 January 2021;

PUBLISHED ONLINE: 04 February 2021.

EDITED BY: Helen Phillips, German Centre for Integrative Biodiversity Research (iDiv), Germany

CITATION: Doblas-Miranda E (2021) Soil Ecosystems Change With Time. Front. Young Minds 9:543498. doi: 10.3389/frym.2021.543498

CONFLICT OF INTEREST: The author declares that the research was conducted in the absence of any commercial or financial relationships that could be construed as a potential conflict of interest.

COPYRIGHT () 2021 Doblas-Miranda. This is an open-access article distributed under the terms of the Creative Commons Attribution License (CC BY). The use, distribution or reproduction in other forums is permitted, provided the original author(s) and the copyright owner(s) are credited and that the original publication in this journal is cited, in accordance with accepted academic practice. No use, distribution or reproduction is permitted which does not comply with these terms.

\section{YOUNG REVIEWERS}

\section{RUTENDO, AGE: 14}

I was born in Zimbabwe and I have two brothers and one sister. I love maths, reading books, and listening to music. When I grow up I want to be either a doctor, scientist, psychologist, or archaeologist.

\section{NOKUTENDA, AGE: 14}

My hobbies are mostly cooking and drawing (anime at most). I have my heart set on being a chef when I am older. I love creative arts. In my spare time I love drawing what my mind expresses. Other times I try and find the time to read a fiction fantasy novel.

\section{AUTHOR}

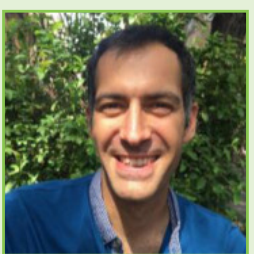

\section{ENRIQUE DOBLAS-MIRANDA}

Enrique has a Ph.D. in biology and is a researcher at CREAF. He is also interested in international cooperation and was the head of the Euro-Mediterranean project called MENFRI, from which he founded an organization that forges partnerships to overcome complex challenges to development and the environment. Enrique has contributed to research on landscape resilience and management in the face of global change, and he also continues his principal line of research about variations in the biodiversity of ecosystems over time. Using several soil invertebrate communities, Enrique has studied the dynamics of forests and croplands in Spain, New Zealand, and Canada. *e.doblas@creaf.uab.cat 